\title{
Curcumin and paclitaxel induce cell death in breast cancer cell lines
}

\author{
GLORIA M. CALAF ${ }^{1,2}$, RICHARD PONCE-CUSI ${ }^{1}$ and FLAVIO CARRIÓN ${ }^{3}$ \\ ${ }^{1}$ Instituto de Alta Investigación, Universidad de Tarapacá, Arica 10000, Chile; ${ }^{2}$ Center for Radiological Research, \\ Columbia University Medical Center, New York, NY 10032, USA; ${ }^{3}$ Programa de Inmunología Traslacional, \\ Facultad de Medicina, Clínica Alemana Universidad del Desarrollo, Santiago, Chile
}

Received February 1, 2018; Accepted June 29, 2018

DOI: $10.3892 /$ or.2018.6603

\begin{abstract}
Breast cancer is one of the major health issues confronting women; however, treatment with conventional chemotherapeutic drugs is limited. Currently, paclitaxel is used as a therapeutic clinical agent to treat breast cancer that exerts antitumor activity in numerous types of cancer cell. Curcumin (diferuloylmethane), a polyphenol derived from turmeric (Curcuma longa), possesses several properties that could enable it to exert an anticancer effect. Previous reports have demonstrated the synergistic effects of several chemotherapeutic drugs in combination with curcumin. Therefore, the aim of the current study was to evaluate cell death induced by curcumin and paclitaxel alone and in combination in human breast cancer cell lines: MCF7, an epithelial and luminal-like adenocarcinoma cell line triple positive for estrogen and progesterone receptor, and MDA-MB-234, a metastatic human breast cancer cell line triple negative for such receptors, as well as MCF-10F as a normal breast cell line. The results indicated that curcumin and paclitaxel induced apoptosis and necrosis, which was demonstrated through multiple methods, including assays of caspase-3/7 activity, Annexin V, poly(ADP-ribose) polymerase-1 activation and protein expression of caspase-3, nuclear factor $(\mathrm{NF})-\kappa \mathrm{B}$ transcription factor and proliferating cell nuclear antigen. The results identified that the combination of curcumin and paclitaxel had a decreased effect on apoptosis in the malignant MDA-MB-231 cell line compared with in MCF7 or MCF-10F. It was demonstrated that the combined treatment with curcumin and paclitaxel resulted in a higher level of apoptosis compared with either substance alone in breast cancer cell lines. Therefore, breast cancer treatment may benefit from the use of a combination of drugs in chemotherapy.
\end{abstract}

Correspondence to: Professor Gloria M. Calaf, Instituto de Alta Investigación, Universidad de Tarapacá, 1520 Calle Antofagasta, Arica 10000, Chile

E-mail: gmc24@cumc.columbia.edu

Key words: curcumin, paclitaxel, breast cancer cell lines, apoptosis

\section{Introduction}

Breast cancer is a heterogeneous disease and one of the major health issues confronting women. Its initiation and progression could be influenced by numerous factors, including environmental and genetic factors (1-3). Currently, treatment with conventional chemotherapeutic drugs for breast cancer is limited, due to issues including poor solubility and multidrug resistance (4). Challenges in breast cancer treatment include the combinations of chemotherapeutic drugs that lead to adverse effects, a high level of heterogeneity from patient to patient, and long-term drug administration, with resistance and recurrence of cancer following treatment $(5,6)$.

Paclitaxel is a first-line therapeutic clinical agent used to treat breast cancer, which exerts its antitumor activity by promoting the polymerization of tubulin and stabilizing the resulting microtubules, causing cell cycle arrest that leads to apoptosis of cancer cells (7). However, paclitaxel resistance often occurs after a short period of treatment, causing a serious problem in chemotherapy that eventually results in the patient succumbing to the disease due to tumor metastasis $(7,8)$.

In recent decades, natural products have formed an important part of drug discovery. Among these natural products, curcumin (diferuloylmethane), a hydrophobic polyphenol derived from turmeric (Curcuma longa) has been used for the treatment of numerous diseases, including cancer (9). Curcumin possesses several beneficial properties, including anti-inflammatory, anti-metastatic and anti-carcinogenic effects, as well as acting as an inhibitor of tumor formation $(10,11)$. Curcumin is considered to be a chemopreventive and chemotherapeutic agent that exerts in vitro anticancer activities in breast cancer cells, inducing apoptosis through modulation of anti- and pro-apoptotic proteins such as B-cell lymphoma 2 (Bcl-2) and Bax, respectively $(10,11)$.

Apoptosis, a type of programmed cell death, is an essential process for regulating homeostasis by eliminating redundant and abnormal cells, and is associated with various diseases, particularly cancer (12). Apoptosis is deregulated in carcinoma, thus, is one of the most studied processes in cancer therapy. In general, apoptosis is controlled by two principal pathways, including the death receptor-mediated (extrinsic) and the mitochondrial-dependent (intrinsic) pathways (13). The latter process is initiated by loss of membrane integrity 
and mitochondrial depolarization, which is regulated by members of the Bcl-2 protein family, triggering the release of cytochrome $c$ into the cytosol, thereby activating caspase- 3 as an effector (13).

Poly(ADP-ribose) polymerase-1 (PARP-1) is another molecule involved in several key biological processes, including apoptosis, cell proliferation control, replication and DNA damage repair (14). PARP is a target of caspase protease activity and is also associated with apoptosis. When PARP detects DNA damage, it is auto-modified and recruits repair factors to the DNA damage sites $(15,16)$. Defects in DNA repair lead to genomic instability and play a critical role in cancer development. Abnormal PARP-1 expression has been reported in various cancer types; increased PARP-1 expression was noted in various cell lines exhibiting tumor progression (14).

Nuclear factor $-\kappa \mathrm{B}(\mathrm{NF}-\kappa \mathrm{B})$, a protein complex that controls transcription of DNA, is involved in modulation of inflammatory response through expression of multiple proinflammatory proteins (17). Tumor cells may enhance NF- $\mathrm{BB}$ activity through increasing cytokine release from stromal cells and fibroblasts in the tumor microenvironment. $\mathrm{NF}-\kappa \mathrm{B}$ overexpression has largely been manifested in triple-negative breast cancer (17). A previous study reported constitutive activation of $\mathrm{NF}-\kappa \mathrm{B}$, resulting in overexpression of anti-apoptotic genes in breast cancer. However, the precise mechanisms for activation of $\mathrm{NF}-\kappa \mathrm{B}$ are not clear (18).

The function of proliferating cell nuclear antigen (PCNA) is essential for the maintenance of genomic integrity in actively growing cells. PCNA serves key functions in the metabolism of nucleic acid. Its primary function is in DNA replication, but it is also involved in RNA transcription, chromatin assembly, cell cycle control and DNA excision repair (19). PCNA is expressed in actively proliferative human cancer cells, and it is identical to a 'cyclin' protein identified in cell proliferation (20).

In the current study, we aimed to ascertain whether curcumin and paclitaxel induced apoptosis, analyzed by protein expression and flow cytometry, in MCF-10F MCF7 and MDA-MB-234 cell lines. MCF-10F is an immortalized breast cell line that retains all of the characteristics of normal epithelium in vitro, including anchorage-dependence, noninvasiveness and non-tumorigenicity in nude mice. MCF7 is an epithelial and luminal-like adenocarcinoma cell line triple positive for estrogen and progesterone receptor. MDA-MB-234 is a metastatic human breast cancer cell line triple negative for such receptors. The aim of the current study was to evaluate the effect of curcumin and paclitaxel in human breast cancer cell lines on loss of membrane integrity, caspase expression, PARP function and NF- $\mathrm{B}$ expression, and their associated effects on apoptosis.

\section{Materials and methods}

Breast cancer cell lines. The MCF-10F cell line [American Type Culture Collection (ATCC), Manassas, VA, USA] was grown in DMEM/F-12 (1:1) medium supplemented with antibiotics (100 U/ml penicillin, $2.5 \mu \mathrm{g} / \mathrm{ml}$ amphotericin B and $100 \mu \mathrm{g} / \mathrm{ml}$ streptomycin; all from Thermo Fisher Scientific, Inc., Waltham, MA, USA), $0.5 \mu \mathrm{g} / \mathrm{ml}$ hydrocortisone (Sigma-Aldrich; Merck KGaA, Darmstadt, Germany),
$10 \mu \mathrm{g} / \mathrm{ml}$ of $5 \%$ equine serum (Biofluids, Inc., Rockville, MD, USA) and $0.02 \mu \mathrm{g} / \mathrm{ml}$ epidermal growth factor (Collaborative Research, Inc., Bedford, MA, USA). MCF7 cells (HTB-22 ${ }^{\mathrm{TM}}$; ATCC) were grown in Minimum Essential Medium supplemented with $10 \%$ fetal bovine serum (FBS). MDA-MB-231 cells (HTB-26 ${ }^{\mathrm{TM}}$; ATCC) were grown in RPMI supplemented also with $10 \%$ FBS. The cells were incubated at $37^{\circ} \mathrm{C}$ with $5 \%$ $\mathrm{CO}_{2}$ until reaching $70 \%$ confluence. Curcumin and paclitaxel (Sigma-Aldrich; Merck KGaA) were dissolved in dimethyl sulfoxide (DMSO) (0.1\%). All treatments were performed at $37^{\circ} \mathrm{C}$. Cells were harvested and seeded at $4 \times 10^{5}$ cells $/ \mathrm{ml}$ culture medium into T75 flasks (Corning Costar, Corning, NY, USA). After a 24-h pre-incubation period allowing cells to attach, the culture medium was replaced by either medium without drugs or medium with $30 \mu \mathrm{M}$ curcumin and/or $10 \mathrm{nM}$ paclitaxel for $48 \mathrm{~h}$.

CellEvent Caspase-3/7 assay. To determine apoptosis by activation of caspase 3/7, the CellEvent Caspase-3/7 green detection reagent kit (Thermo Fisher Scientific, Inc.) was used. The kit contains a substrate for activated caspases 3 and 7, producing a fluorogenic response indicative of apoptosis. This was used together with the SYTOX ${ }^{\circledR}$ AADvanced dead cell stain (Thermo Fisher Scientific, Inc.) to discriminate necrotic from live cells. The fluorescence emission maximum of the dye was at $\sim 520 \mathrm{~nm}$. The acquisition process started following 30 min of incubation and analysis was performed using Beckman Coulter FC500 Flow Cytometry system with CXP software (Beckman Coulter, Inc., Brea, CA, USA) within $1 \mathrm{~h}$. Experiments were performed in triplicate.

7-Amino actinomycin D (7-AAD)/Annexin $V$ assay. Phosphatidylserine (PS) is located inside the cell membrane in normal cells and is transferred to the surface during the early stage of cell apoptosis. Annexin V, a Ca ${ }^{2+}$-dependent phospholipid binding protein, has a strong binding affinity for PS. An Annexin V-FITC/7-AAD staining kit was used to assess curcumin or paclitaxel-induced cell apoptosis. MCF7 and MDA-MB-231 cell lines were cultured to $70 \%$ confluence, and then curcumin and/or paclitaxel was added. After $48 \mathrm{~h}$, cells were harvested and washed twice with pre-cooled PBS and then resuspended in $1 \mathrm{X}$ binding buffer at a concentration of $1 \times 10^{6}$ cells $/ \mathrm{ml}$. Then, $100 \mu 1$ of this solution $\left(1 \times 10^{5}\right.$ cells $)$ was mixed with $10 \mu \mathrm{l}$ Annexin V-FITC and $20 \mu \mathrm{l}$ 7-AAD (Beckman Coulter), according to the manufacturer's instructions. The mixed solution was incubated at room temperature $\left(25^{\circ} \mathrm{C}\right)$ in the dark for $15 \mathrm{~min}$. Then, $400 \mu \mathrm{l} 1 \mathrm{X}$ dilution buffer was added to each tube. Analysis was performed using Beckman Coulter FC500 Flow Cytometry system with CXP software (Beckman Coulter) within $1 \mathrm{~h}$. Experiments were performed in triplicate.

PARP cleavage. PARP cleavage was used to detect DNA damage in the cell cultures (PE Mouse Anti-Cleaved PARP, Asp214; BD Biosciences, San Diego, CA, USA). Curcumin $(30 \mu \mathrm{M})$ and/or paclitaxel $(10 \mathrm{nM})$ were added per $1 \times 10^{6}$ proliferating breast cells. Cells were incubated for $48 \mathrm{~h}$ at $37^{\circ} \mathrm{C}$. Cells (treated and untreated) were washed with cold $\mathrm{PBS}$; then re-suspended in Cytofix/Cytoperm ${ }^{\mathrm{TM}}$ solution at $2 \times 10^{6}$ cells $/ \mathrm{ml}$. Cells were kept for $20 \mathrm{~min}$ on ice. Cells were 
A

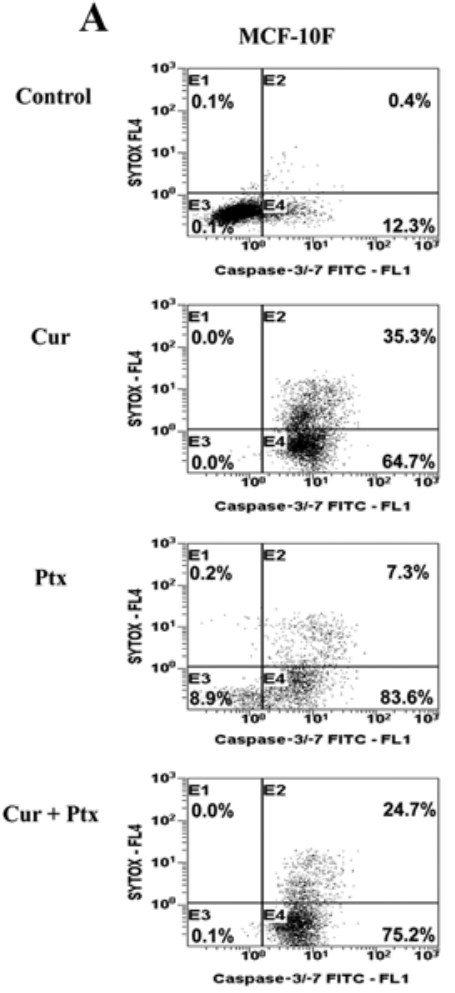

B
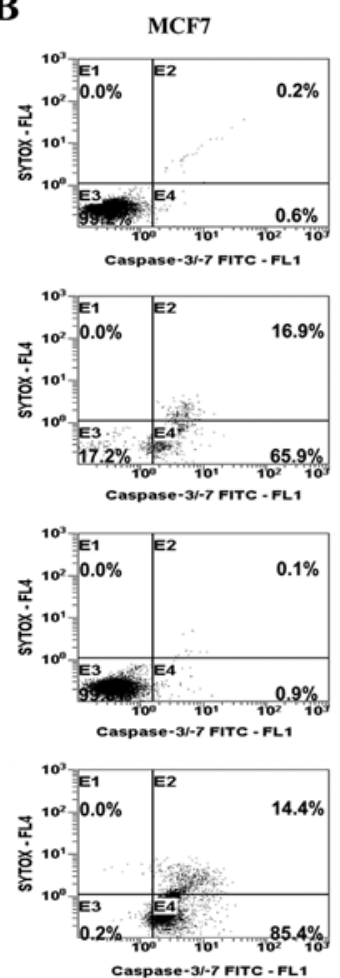

C
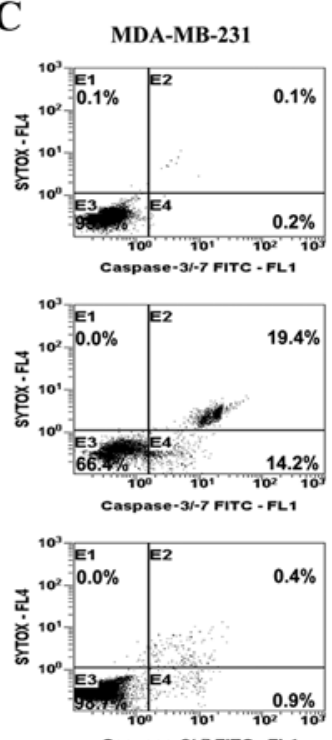

Caspase-3/-7 FITC - FL1

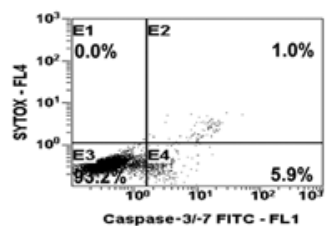

D

घSYTOX $*$ /Casp-3/-7" (live cells) BSYTOX $/$ Casp $-3 /-7^{+}$(apoptotic cells)

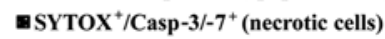
MCF-10F

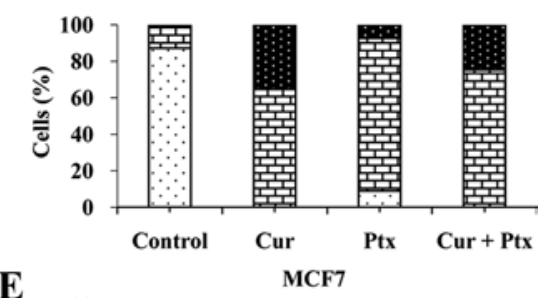

$\mathbf{E}$

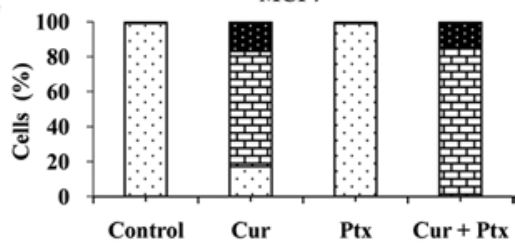

F

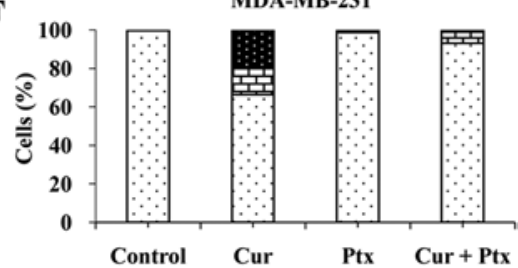

Figure 1. (A-C) Effect of curcumin (Cur) and paclitaxel (Ptx) on apoptosis in the MCF-10F, MCF7 and MDA-MB-231 cell lines, analyzed by labeling with CellEvent Caspase 3/7 kit for apoptosis detection. (D-F) Histograms represent the percentage of cell distribution. Data are presented as the mean \pm standard error of the mean of three independent experiments.

pelleted, aspirated and the Cytofix/Cytoperm solution was discarded. Then, cells were washed twice at room temperature with $0.5 \mathrm{ml} \mathrm{Perm} / \mathrm{Wash}^{\mathrm{TM}}$ buffer per $1 \times 10^{6}$ cells, and the supernatants were discarded. Cells were re-suspended in Perm/Wash buffer at $10 \times 10^{6} / \mathrm{ml}$. Test samples were aliquoted at $1 \times 10^{6}$ cells per 100- $\mu 1$ test. Antibody (20 $\mu \mathrm{l}$ per test) was added, and incubated for $30 \mathrm{~min}$ at room temperature. Each test was washed in $1.0 \mathrm{ml} \mathrm{Perm} /$ Wash Buffer and the supernatant was discarded. Each test was re-suspended in $0.5 \mathrm{ml} \mathrm{Perm} /$ Wash Buffer and analyzed by flow cytometry. Analysis was performed using Beckman Coulter FC500 Flow Cytometry system with CXP software (Beckman Coulter) within $1 \mathrm{~h}$. Experiments were performed in triplicate.

Western blot analysis. To determine protein expression, western blotting was performed. Cells were lysed with $1 \mathrm{ml}$ lysis buffer (pH 7.2; Tris Base, $50 \mathrm{mM}), \mathrm{NaCl}(100 \mathrm{mM})$, EDTA $(1 \mathrm{mM})$, orthovanadate $(1 \mathrm{mM})$, PMSF $(1 \mathrm{mM})$ and Triton X-100 (0.1\%) and centrifuged (13,200 rpm, $15 \mathrm{~min})$. The supernatant with cellular proteins was dissolved in SDS-PAGE sample solution containing $60 \mathrm{mM}$ Tris ( $\mathrm{pH} 6.5$ ), $10 \%(\mathrm{w} / \mathrm{v})$ glycerol, $5 \%(\mathrm{w} / \mathrm{v}) \beta$-mercaptoethanol, $20 \%(\mathrm{w} / \mathrm{v})$ SDS, and $0.025 \%(\mathrm{w} / \mathrm{v})$ bromophenol blue and denatured by boiling $(2 \times 5 \mathrm{~min})$, and vortex mixing $(2 \times 30 \mathrm{sec})$. The total amount of protein was $50 \mu \mathrm{g}$ in each lane with standard protein markers (Bio-Rad Laboratories, Inc., Hercules, CA, USA). Following fractionation by SDS-PAGE on gels $(7 \times 14 \mathrm{~cm})$, proteins were electro-blotted onto PVDF membranes (GE Healthcare, Chicago, IL, USA) using a blotting apparatus (Bio-Rad Laboratories, Inc.). Membranes were blocked for
$2 \mathrm{~h}$ in $10 \%$ non-fat dry milk-TBS- $0.1 \%$ Tween-20 and then incubated for $2 \mathrm{~h}$ at room temperature with corresponding primary antibodies (1:200): NF- $\mathrm{kB}$ (sc-53744), caspase-3 (sc-7148), PCNA (sc-56), and $\beta$-actin (sc-47778). This was followed by incubation with secondary peroxidase-conjugated mouse IgG (1:5,000; Cell Signaling Technology, Inc., Danvers, MA, USA) in 5\% non-fat dry milk-TBS-0.1\% Tween-20. All steps were performed at room temperature, and blots were rinsed between incubation steps with TBS- $0.1 \%$ Tween-20. Cell blots were probed with mouse anti $\beta$-actin antibody as control. Immunoreactive bands were visualized using the $\mathrm{ECL}^{\mathrm{TM}}$ Western Blotting Detection Reagent detection method (GE Healthcare) and exposure of the membrane to X-ray film. Protein determination was performed using the Bicinchoninic Acid Method (Bio-Rad Laboratories, Inc.) with BSA as the standards. Experiments were performed in triplicate.

Statistical analysis. Data are expressed as the average \pm standard error of the mean. Comparisons between untreated and treated groups were analyzed by analysis of variance and Dunnett's test. $\mathrm{P}<0.05$ was considered to indicate a statistically significant difference. Assays were performed at least three times independently.

\section{Results}

The present study evaluated the apoptotic effect of curcumin, paclitaxel and their combined administration in human breast cancer cell lines MCF-10F, MCF7 and MDA-MB-231. Apoptosis and necrosis were analyzed by flow cytometry using 
A
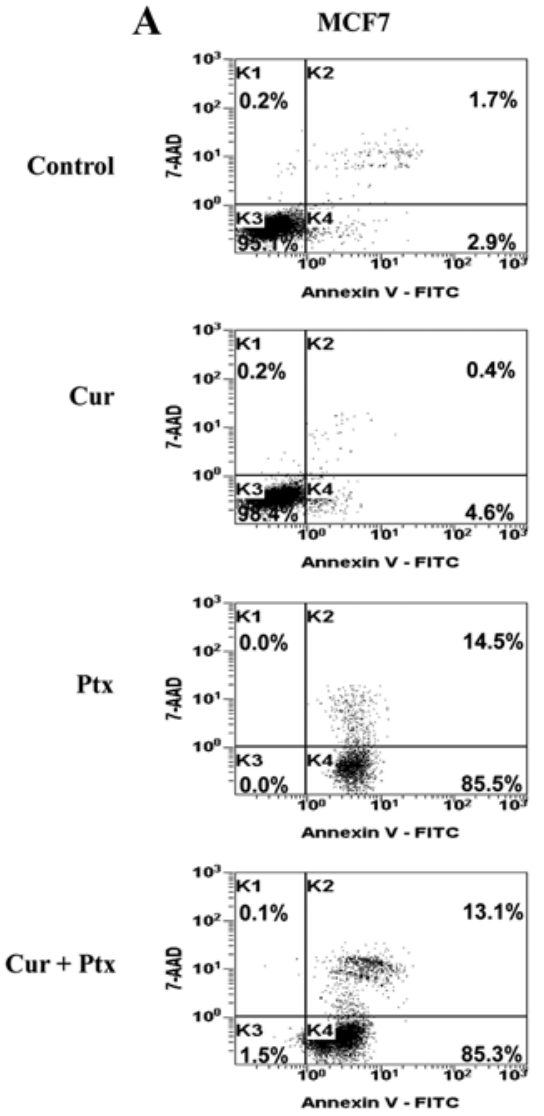

B
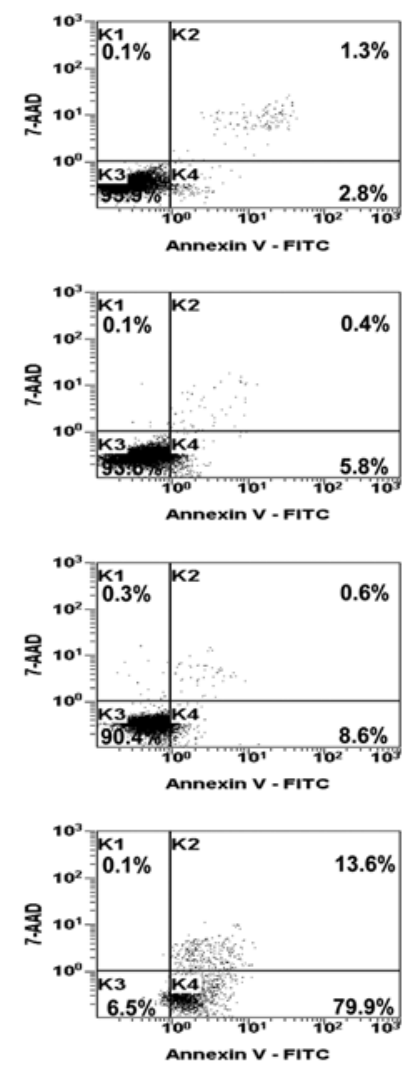

C

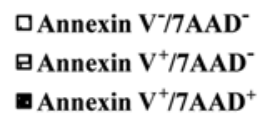

DAnnexin $\mathrm{V}^{*} / 7 \mathrm{AAD}^{-}$

BAnnexin $\mathrm{V}^{+} / 7 \mathrm{AAD}^{-}$

- Annexin $\mathrm{V}^{+} / 7 \mathrm{AAD}^{+}$

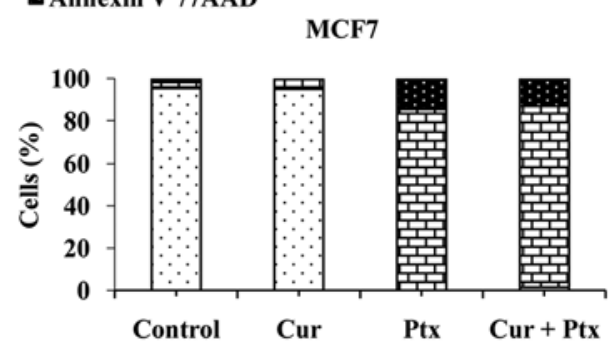

D

MDA-MB-231

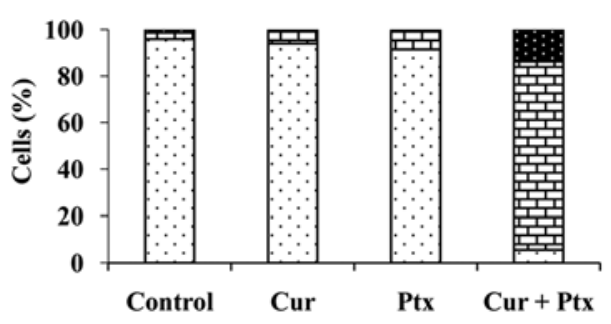

Figure 2. (A and B) Flow cytometric analysis for membrane integrity of breast cancer cells by 7-AAD/Annexin V kit. Apoptotic effects of curcumin (Cur) and paclitaxel (Ptx) were evaluated in (A) MCF7 and (B) MDA-MB-231 cell lines compared with their control. Upper left quadrant (K1) indicates cells undergoing necrosis; upper right quadrant (K2), cells at the end stage of apoptosis; lower left quadrant (K3) indicates cells that are viable, or exhibit no measurable apoptosis and lower right quadrant (K4) indicates cells undergoing apoptosis. (C and D) Histograms represent the percentage of cell distribution. The percentage of cells in apoptosis was determined by CXP software.

the Cell Event Caspase-3/7 kit and 7-AAD/Annexin V assay, and by western blotting, analysis of PARP protein activation, and evaluation of cell proliferation via PCNA.

Analysis of caspase 3/7 activity. A distinctive feature of the early stages of apoptosis is the activation of caspases. This was evaluated in the current study using the Cell Event Caspase-3/7 kit. Fig. 1A-F shows dot-plot and representative graphs with results that indicate the effect of curcumin, paclitaxel and the combined treatment on caspase 3/7 activity, as analyzed by flow cytometry. Fig. 1A indicates that paclitaxel induced a higher level of apoptosis (83.6\%) compared with curcumin $(64.7 \%)$ or the combined treatment $(75.2 \%)$ in the MCF-10F cell line. Paclitaxel alone induced only $7.3 \%$ of necrosis. However, curcumin alone induced $35.3 \%$ and the combined treatment induced $24.7 \%$ necrosis in the MCF-10F cell line (Fig. 1A and D). However, the results in Fig. 1B indicate that curcumin $(65.9 \%)$ and the combined treatment (85.4\%) induced a higher level of apoptosis compared with paclitaxel alone (0.9\%) in the MCF7 cell line and there was no significant induction of necrosis by any treatment given (Fig. 1B and E). As indicated in Fig. 1C, curcumin induced $14.2 \%$ apoptosis and $19.4 \%$ necrosis in the MDA-MB-231 cell line. There was no evidence of necrosis following paclitaxel or combined treatment in the MDA-MB-231 cell line (Fig. 1C and F).
Analysis of cell membrane integrity. The loss of membrane integrity was analyzed by 7-AAD/Annexin $\mathrm{V}$ assay (Fig. 2A-D). As shown in Fig. 2A and C, paclitaxel or the combined treatment induced increased levels of apoptosis (85.5 and $85.3 \%$, respectively) compared with curcumin alone (4.6\%) in the MCF7 cell line. In contrast, no significant effect on apoptosis was observed following paclitaxel or curcumin treatment in the MDA-MB-231 cell line compared with the control (Fig. 2B). However, combined treatment with paclitaxel and curcumin induced $79.9 \%$ apoptosis (Fig. 2B and D). However, necrosis was not observed in these two cell lines.

Analysis of PARP activation. Since PARP is a target of caspase protease activity and is also associated with apoptosis, its activation was evaluated in the present study (Fig. 3A-F). A total of $99.5 \%$ of cells treated with curcumin, paclitaxel and the combined treatment had induced PARP-cleavage activation in the MCF-10F cell line (Fig. 3A). A graph of these results is presented in Fig. 3D. A similar percentage of cells exhibited PARP activation in the MCF7 cell line, as indicated in Fig. 3B. A graph of these results is presented in Fig. 3E. On the other hand, only curcumin treatment induced PARP activation in the MDA-MB-231 cell line (Fig. 3C).

Western blot analysis. The results of the western blot analysis of the MCF7 and MDA-MB-231 cell lines following treat- 
A

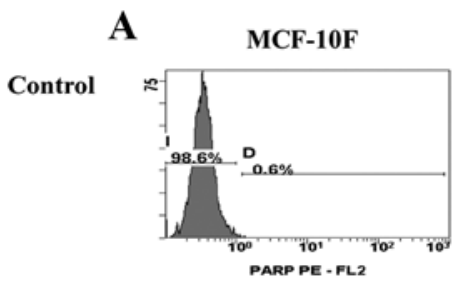

Cur

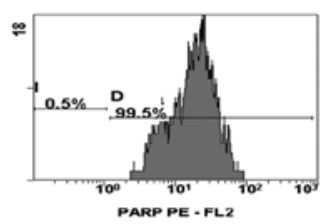

Ptx

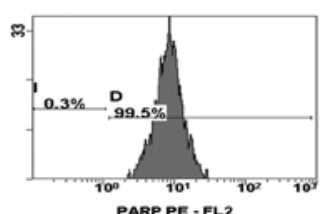

Cur + Px

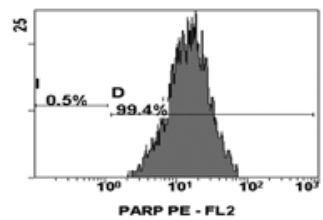

B
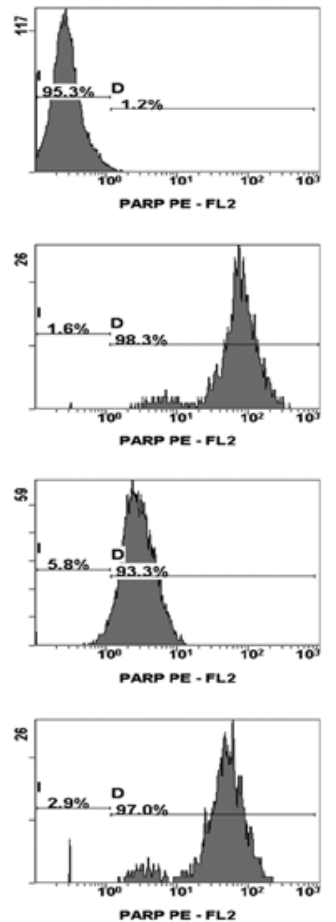

C
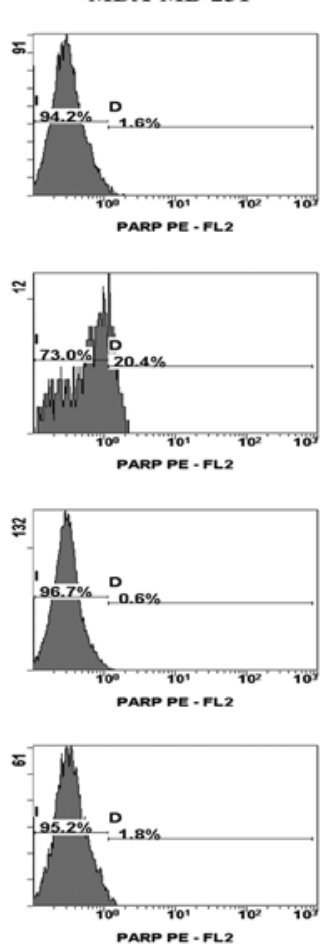

D

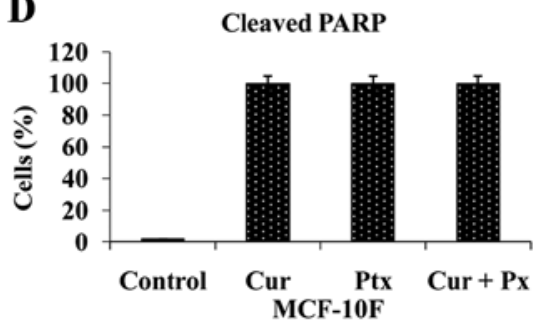

E
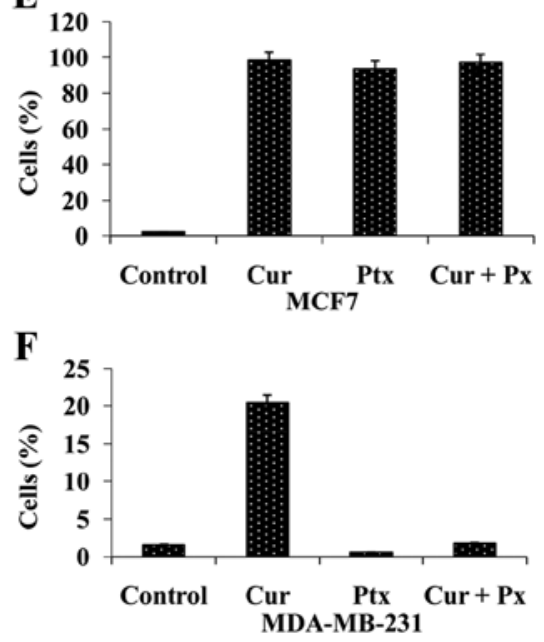

Figure 3. (A-C) Effect of curcumin (Cur) and paclitaxel (Ptx) on cleavage of PARP in MCF-10F, MCF7 and MDA-MB-231 cell lines, analyzed by flow cytometry. (D-F) Histograms represent the percentage of cleaved PARP.

ment with curcumin alone, paclitaxel alone and combined with paclitaxel are shown in Fig. 4A-F. Curcumin alone and combined with paclitaxel significantly decreased caspase-3 protein expression in the MCF7 cells ( $\mathrm{P}<0.05$; Fig. 4A), as analyzed by western blotting. Curcumin alone and the combined treatment significantly decreased caspase-3 expression in the MDA-MB-231 cell line ( $\mathrm{P}<0.01$; Fig. 4D).

$\mathrm{NF}-\kappa \mathrm{B}$ is a transcription factor that regulates the expression of hundreds of genes that are involved in regulating cell growth and apoptosis pathways in the cytoplasm. As indicated in Fig. 4B, curcumin and paclitaxel alone significantly decreased NF- $\kappa \mathrm{B}$ protein expression in the MCF7 cell line $(\mathrm{P}<0.01)$. By contrast, paclitaxel alone significantly increased $\mathrm{NF}-\kappa \mathrm{B}$ protein expression in the MDA-MB-231 cell line $(\mathrm{P}<0.05$; Fig. 4E).

PCNA was analyzed in the current study since it is involved in numerous molecular pathways responsible for the life and death of mammalian cells. As indicated in Fig. 4C, curcumin or paclitaxel did not induce any significant changes in PCNA protein expression in the MCF7 cell line. However, as shown in Fig. 4F, curcumin alone significantly inhibited PCNA protein expression in comparison with the control in MDA-MB-231 cells $(\mathrm{P}<0.05)$.

\section{Discussion}

In the present study, the induction of apoptosis was studied through several processes that indicate cell death, cell necrosis, activation of proteins and protein expression. Among the substances analyzed, curcumin and the combined treatment with curcumin and paclitaxel induced a lower rate of apoptosis compared with paclitaxel alone in the MCF-10F cell line. However, curcumin and the combined treatment induced a higher rate of apoptosis compared with paclitaxel alone in the MCF7 cell line, and there was no induction of necrosis by any treatment. It was notable that there was no evidence of necrosis following paclitaxel or combined treatment in the MDA-MB-231 cell line.

In apoptosis, caspase- 3 is the most important effector. This molecule is inactive inside the cell. Once the apoptotic cascade is triggered, it undergoes cleavage and subsequent activation (21). The current study indicated that curcumin alone and combined with paclitaxel decreased caspase- 3 protein expression in the MCF7 and MDA-MB-231 cell lines. Similar results have been obtained with curcumin in the Tumor2 cell line (22). On the other hand, drugs such as 5-FU were found to increase caspase-3 expression in Tumor 2 and MDA-MB-231 cell lines as an indication of apoptosis (23). The ability of curcumin to induce apoptosis in tumor cells, and/or potentiate apoptosis induction by classical chemotherapeutic drugs, supports its potential in anticancer therapies. It has previously been indicated that curcumin activates caspase-3 (24). Others have found that the combination of Trichostatin A with $20 \mathrm{mM}$ of curcumin increased caspase-3 cleavage products (24). It has been demonstrated that dimethoxy curcumin, an analogue of curcumin, has good chemical and metabolic stability, influencing the activation of caspase-3 in vitro and in vivo (25). It has also been reported that combined paclitaxel and curcumin enhances caspase-3/7 activities in SKOV3 and SKOV3TR cells (26).

It is interesting to note that apoptosis may be evaluated via two methods involving caspase 3/7 and Annexin V; however, 
MCF7

MDA-MB-231

\section{Caspase-3}

A
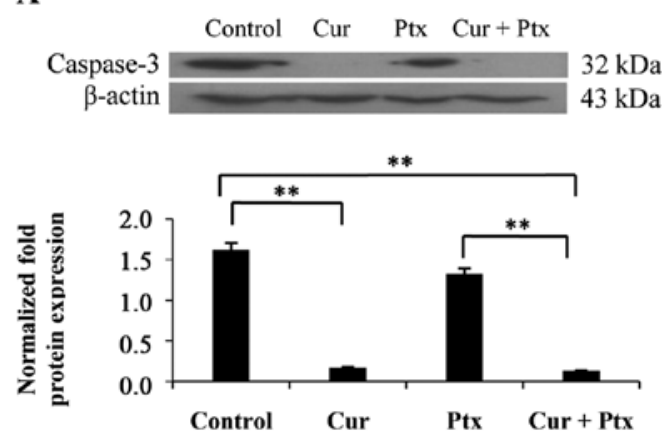

B
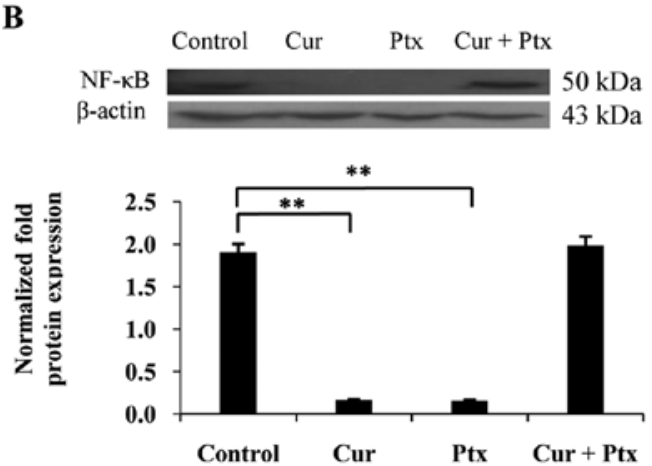

PCNA

C
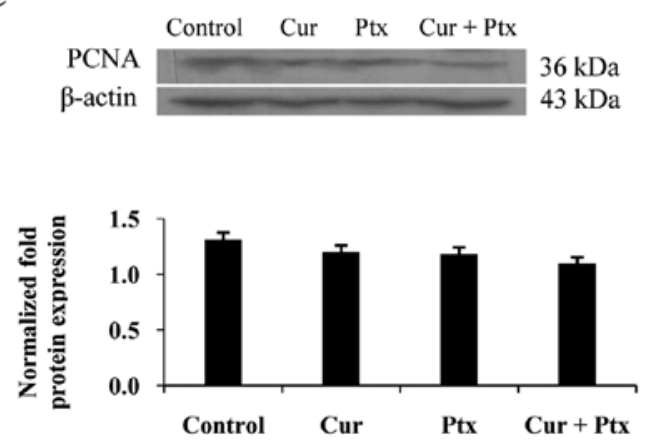

D
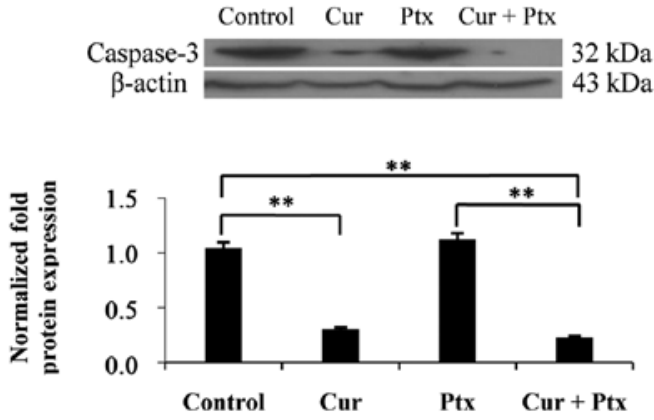

NF-KB

$\mathbf{E}$
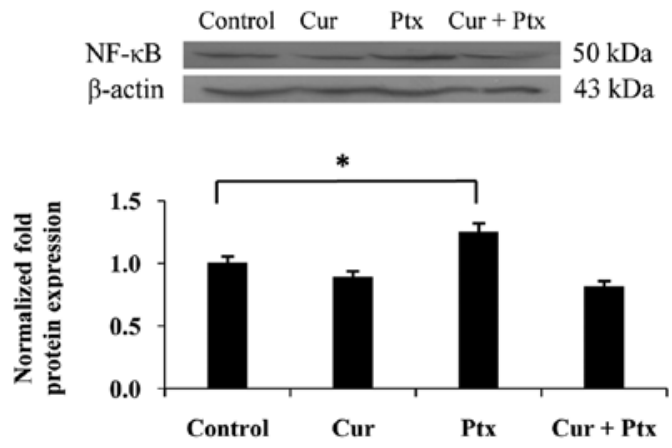

Figure 4. Effect of curcumin (Cur) and paclitaxel (Ptx) on caspase-3, NF- $\kappa$ B and PCNA protein expression in (A-C) MCF7 cells and (D-F) MDA-MB-231 cells, as analyzed by western blotting. Bars represent the mean \pm standard error of the mean of three independent experiments. ${ }^{*} \mathrm{P}<0.05$, ${ }^{* *} \mathrm{P}<0.01$ vs. its counterparts. $\beta$-actin was used as an endogenous control protein.

in principle these two processes detect apoptosis in different ways. Caspase 3/7 determines apoptosis through activation of effector caspases, while Annexin V is related to loss of cell membrane integrity evidenced by phosphatidylserine migration from the inner to outer cellular surface of the membrane.

Paclitaxel $(10 \mathrm{nM})$ combined with curcumin $(30 \mu \mathrm{M})$ induced loss of membrane integrity, indicating increased apoptosis in comparison with curcumin alone in the MCF7 cell line. However, only combined treatment induced apoptosis in the MDA-MB-231 cell line. Previous results indicated that the concentrations used were similar (27-29). Other studies have demonstrated the apoptotic effect of curcumin combined with paclitaxel via decreased gene expression of Bcl-xL in comparison with the control or with either substance alone in MCF7 and MDA-MB-231 cell lines. The results indicated that curcumin or paclitaxel alone, as well as combined treatment, decreased $\mathrm{Bcl}-2$ and increased Bax protein expression in comparison with the control in MCF7 cells (27).

Activation of PARP was evaluated in the current study as a target of caspase protease activity, and is associated with apoptosis. It was notable to observe that $99.5 \%$ of cells treated with curcumin, paclitaxel or combined treatment induced PARP activation in the MCF-10F cell line. A similar percentage of cells was observed to induce PARP activation in the MCF7 cell line. Previous results found that PARP-1 was cleaved upon curcumin treatment in the malignant and tumorigenic Tumor2 cell line from an experimental breast cancer model exposed to ionizing radiation (alpha particles) and estradiol (28-30). This 
is similar to the results for the metastatic MDA-MB-231 cell line in the current study, in which only curcumin treatment induced PARP activation or cleavage.

Previous studies have indicated that curcumin is a pharmacologically safe compound, and it has therapeutic potential in preventing breast cancer metastasis, possibly through suppression of $\mathrm{NF}-\kappa \mathrm{B}$, an important transcription factor. It has been demonstrated to be involved in regulating apoptosis. The current results indicated that either curcumin or paclitaxel alone significantly decreased $\mathrm{NF}-\kappa \mathrm{B}$ protein expression in the MCF7 cell line, and combined treatment slightly decreased $\mathrm{NF}-\kappa \mathrm{B}$ protein expression in the MDA-MB-231 cell line. However, paclitaxel alone increased $\mathrm{NF}-\kappa \mathrm{B}$ protein expression in the MDA-MB-231 cell line, indicating possible resistance to this drug that is counteracted by curcumin when they are combined. It has previously been observed that curcumin suppresses NF- $\kappa \mathrm{B}$ activation, and most chemotherapeutic agents activate genes that mediate proliferation, which is why it was ascertained whether curcumin would potentiate the effect of chemotherapy in breast cancer cell lines in the current study. Curcumin decreased expression of $N F-\kappa B$ in the current study, supporting the conclusion of other reports that the mechanism of proliferation and inhibition induced by combined effect of paclitaxel and curcumin is through $\mathrm{NF}-\kappa \mathrm{B}$ inhibition (27).

Previous results indicated that $\mathrm{NF}-\kappa \mathrm{B}$ is altered by curcumin (29). Since curcumin suppresses NF- $\kappa$ B activation and most chemotherapeutic agents activate genes that mediate cell survival, proliferation, invasion and metastasis, it was analyzed whether curcumin would potentiate the effect of chemotherapy in breast cancer cell lines (27). Curcumin decreased expression of $\mathrm{NF}-\kappa \mathrm{B}$, supporting the conclusion of other reports that the mechanism of growth inhibition induced by combined effect of paclitaxel and curcumin is through NF- $\kappa \mathrm{B}$ inhibition. It was previously demonstrated that curcumin suppresses the paclitaxel-induced $N F-\kappa B$ pathway in breast cancer cells by inhibiting lung metastasis of human breast cancer in nude mice (27). The current results indicated that the $\mathrm{NF}-\kappa \mathrm{B}$ gene and protein expression increased in the MCF-7 and MDA-MB-231 cells compared with controls.

In the current study, PCNA protein expression was not altered by curcumin or paclitaxel in the MCF7 cell line, but was inhibited in MDA-MB-231 by curcumin alone. These results are similar to those published by Calaf and Hei (28), in which curcumin inhibited PCNA protein expression in an in vitro breast cancer progression model. It may be concluded that both curcumin and paclitaxel induce apoptosis by regulating $\mathrm{NF}-\kappa \mathrm{B}$ expression in malignant breast cell lines, since this molecule is a master modulator of several mechanisms, including apoptosis and cell proliferation.

\section{Acknowledgements}

The technical support of Georgina Vargas Marchant, Guiliana Rojas and Leodán A. Crispin is greatly appreciated.

\section{Funding}

This study was supported by a grant from Universidad de Tarapacá, Convenio de desempeño UTA1117 (GMC).

\section{Availability of data and materials}

The datasets used during the present study are available from the corresponding author upon reasonable request.

\section{Authors' contributions}

GMC, RPC, FC conceived, designed and performed the study. GMC, RPC, FC wrote, reviewed and edited the manuscript. All authors read and approved the manuscript and agree to be accountable for all aspects of the research in ensuring that the accuracy or integrity of any part of the work are appropriately investigated and resolved.

\section{Ethics approval and consent to participate}

Not applicable.

\section{Patient consent for publication}

Not applicable.

\section{Competing interests}

The authors declare that they have no competing interests.

\section{References}

1. Ferlay J, Soerjomataram I, Dikshit R, Eser S, Mathers C, Rebelo M, Parkin DM, Forman D and Bray F: Cancer incidence and mortality worldwide: Sources, methods and major patterns in GLOBOCAN 2012. Int J Cancer 136: E359-E386, 2015.

2. Jafari SH, Saadatpour Z, Salmaninejad A, Momeni F, Mokhtari M, Nahand JS, Rahmati M, Mirzaei H and Kianmehr M: Breast cancer diagnosis: Imaging techniques and biochemical markers. J Cell Physiol 233: 5200-5213, 2018.

3. Mustacchi G and De Laurentiis M: The role of taxanes in triplenegative breast cancer: Literature review. Drug Des Devel Ther 9: 4303-4318, 2015.

4. Bidkar AP, Sanpui P and Ghosh SS: Efficient induction of apoptosis in cancer cells by paclitaxel-loaded selenium nanoparticles. Nanomedicine (Lond) 12: 2641-2651, 2017.

5. Karimi G, Vahabzadeh M, Lari P, Rashedinia M and Moshiri M: 'Silymarin', a promising pharmacological agent for treatment of diseases. Iran J Basic Med Sci 14: 308-317, 2011

6. Razavi-Azarkhiavi K, Iranshahy M, Sahebkar A, Shirani K and Karimi G: The protective role of phenolic compounds against doxorubicin-induced cardiotoxicity: A comprehensive review. Nutr Cancer 68: 892-917, 2016.

7. Stage TB, Bergmann TK and Kroetz DL: Clinical pharmacokinetics of paclitaxel monotherapy: An updated literature review. Clin Pharmacokinet 57: 7-19, 2018.

8. Zheng X, Wang C, Xing Y, Chen S, Meng T, You H, Ojima I and Dong Y: SB-T-121205, a next-generation taxane, enhances apoptosis and inhibits migration/invasion in MCF-7/PTX cells. Int J Oncol 50: 893-902, 2017.

9. Wang Y, Yu J, Cui R, Lin J and Ding X: Curcumin in treating breast cancer: A review. J Lab Autom 21: 723-731, 2016.

10. Robles-Escajeda E, Das U, Ortega NM, Parra K, Francia G, Dimmock JR, Varela-Ramirez A and Aguilera RJ: A novel curcumin-like dienone induces apoptosis in triple-negative breast cancer cells. Cell Oncol (Dordr) 39: 265-277, 2016.

11. Ko EY and Moon A: Natural products for chemoprevention of breast cancer. J Cancer Prev 20: 223-231, 2015.

12. Księżakowska-Łakoma $K$, Żyła M and Wilczyński JR: Mitochondrial dysfunction in cancer. Prz Menopauzalny 13: 136-144, 2014.

13. Cui L, Bu W, Song J, Feng L, Xu T, Liu D, Ding W, Wang J, Li C, Ma B, et al: Apoptosis induction by alantolactone in breast cancer MDA-MB-231 cells through reactive oxygen speciesmediated mitochondrion-dependent pathway. Arch Pharm Res 41: 299-313, 2018. 
14. Li J, Dou D, Li P, Luo W, Lv W, Zhang C, Song X, Yang Y, Zhang Y, Xu Y, et al: PARP-1 serves as a novel molecular marker for hepatocellular carcinoma in a Southern Chinese Zhuang population. Tumour Biol 39: 1010428317706914, 2017.

15. Lucarini L, Durante M, Lanzi C, Pini A, Boccalini G, Calosi L, Moroni F, Masini E and Mannaioni G: HYDAMTIQ, a selective PARP-1 inhibitor, improves bleomycin-induced lung fibrosis by dampening the TGF- $\beta$ /SMAD signalling pathway. J Cell Mol Med 21: 324-335, 2017.

16. Schuhwerk H, Atteya R, Siniuk K and Wang ZQ: PARPing for balance in the homeostasis of poly(ADP-ribosyl)ation. Semin Cell Dev Biol 63: 81-91, 2017.

17. Darvishi B, Farahmand L, Eslami-S Z and Majidzadeh-A K $\mathrm{NF}-\kappa \mathrm{B}$ as the main node of resistance to receptor tyrosine kinase inhibitors in triple-negative breast cancer. Tumour Biol 39: $1010428317706919,2017$.

18. Baskari S, Govatati S, Madhuri V, Nallabelli N, K PM, Naik S, Poornachandar, Balka S, Tamanam RR and Devi VR: Influence of autocrine growth hormone on NF- $\kappa \mathrm{B}$ activation leading to epithelial-mesenchymal transition of mammary carcinoma. Tumour Biol 39: 1010428317719121, 2017.

19. Juríková M, Danihel L', Polák Š and Varga I: Ki67, PCNA, and MCM proteins: Markers of proliferation in the diagnosis of breast cancer. Acta Histochem 118: 544-552, 2016.

20. Wang SC: PCNA: A silent housekeeper or a potential therapeutic target? Trends Pharmacol Sci 35: 178-186, 2014.

21. Lossi L, Cocito C, Alasia S and Merighi A: Ex vivo imaging of active caspase 3 by a FRET-based molecular probe demonstrates the cellular dynamics and localization of the protease in cerebellar granule cells and its regulation by the apoptosis-inhibiting protein survivin. Mol Neurodegener 11: 34, 2016.
22. Gallardo M and Calaf GM: Curcumin and epithelial-mesenchymal transition in breast cancer cells transformed by low doses of radiation and estrogen. Int J Oncol 48: 2534-2542, 2016.

23. Ponce-Cusi R and Calaf GM: Apoptotic activity of 5-fluorouracil in breast cancer cells transformed by low doses of ionizing $\alpha$-particle radiation. Int J Oncol 48: 774-782, 2016.

24. Yan G, Graham K and Lanza-Jacoby S: Curcumin enhances the anticancer effects of trichostatin a in breast cancer cells. Mol Carcinog 52: 404-411, 2013.

25. Chen D, Dai F, Chen Z, Wang S, Cheng X, Sheng Q, Lin J and Chen W: Dimethoxy curcumin induces apoptosis by suppressing survivin and inhibits invasion by enhancing E-cadherin in colon cancer cells. Med Sci Monit 22: 3215-3222, 2016.

26. Ganta S and Amiji M: Coadministration of paclitaxel and curcumin in nanoemulsion formulations to overcome multidrug resistance in tumor cells. Mol Pharm 6: 928-939, 2009.

27. Quispe-Soto ET and Calaf GM: Effect of curcumin and paclitaxel on breast carcinogenesis. Int J Oncol 49: 2569-2577, 2016

28. Calaf GM and Hei TK: Establishment of a radiation- and estrogeninduced breast cancer model. Carcinogenesis 21: 769-776, 2000.

29. Calaf GM, Echiburú-Chau C, Wen G, Balajee AS and Roy D: Effect of curcumin on irradiated and estrogen-transformed human breast cell lines. Int J Oncol 40: 436-442, 2012.

30. Calaf GM, Echiburú-Chau C, Roy D, Chai Y, Wen G and Balajee AS: Protective role of curcumin in oxidative stress of breast cells. Oncol Rep 26: 1029-1035, 2011. 